\title{
CORRELATION BETWEEN COMPRESSIVE STRENGTHS AND WATER ABSORPTION OF FLY ASH CEMENT MORTAR IMMERSED IN WATER
}

\author{
QIAN HUANG ${ }^{1}$, LIANG ZHAO ${ }^{2}$
}

\begin{abstract}
The compressive strength and water absorption of cement mortars with different water-binder ratio $(0.35,0.45$ and 0.55$)$ and fly ash content $(0,10 \%, 20 \%$ and $30 \%)$ under water immersion were investigated, and the correlation between them was further analyzed. The internal microstructure and phase composition of mortar was studied by scanning electron microscopy (SEM) and X-ray diffraction (XRD), respectively. The results show that the inside of mortar mixed with fly ash displayed the loose and porous microstructure. Therefore, the incorporation of fly ash reduced the compressive strength of mortar, especially the early strength, and the strength decreased with the increase of fly ash content, and the water absorption of mortar also increased. There was a linear correlation between the compressive strength and water absorption of mortar with the equation: $f_{\mathrm{c}}=$ $-3.838 \beta+62.332$, where $f_{\mathrm{c}}$ and $\beta$ represented the compressive strength and water absorption, respectively. Therefore, when the water absorption of mortar immersed in water was measured, its corresponding compressive strength could be preliminarily inferred through this equation, which was of great significance for detecting and identifying the stability and safety of hydraulic structures.
\end{abstract}

Keywords: Water Immersion, fly ash cement, compressive strength, water absorption, correlation

\section{INTRODUCTION}

Fly ash is a finely divided dry powder collected by precipitators from flue gases of pulverized coalburning power plants and it has low reactivity [1]. Now days, fly ash is widely used in concrete

\footnotetext{
${ }^{1}$ Assistant Professor., PhD., School of Civil and Architectural Engineering, Yangtze Normal University, Chongqing408100, China, e-mail: qhuang@yznu.edu.cn

${ }^{2}$ Lecturer., PhD, School of Civil and Architectural Engineering, Yangtze Normal University, Chongqing-408100, China, e-mail: jrzhaoliang@163.com (Corresponding author)
} 
production, because the incorporation of fly ash can reduce the hydration heat, improve the workability and durability of concrete [2].

Generally, most researches [3-4] on fly ash concrete are carried out under the standard curing, which is necessary to explore the action mechanism of fly ash on concrete. However, the actual service environment of concrete is very complex, such as high temperature, low temperature, water immersion and dry environment. At present, fly ash has also been widely used in the hydraulic concrete [5-6], so the variation of compressive strength of cement mortars with different waterbinder ratio and fly ash content under water immersion was investigated in this paper. In addition, the mechanical strength, permeability, thermal conductivity and durability of materials depend on the pore structure parameters such as porosity and pore diameter distribution [7-8]. The testing methods of pore structure of cement-based materials include mercury intrusion method, nitrogen adsorption method, alternating current impedance method and evaporable water content method. Therefore, the water absorption of mortar was also measured to reflect the pore structure characteristics of the material in this investigation, and the correlation between water absorption and compressive strength was further analyzed.

\section{EXPERIMENTAL METHOD AND PROCESS}

\subsection{MATERIALS AND MORTAR PREPARATION}

Ordinary Portland cement (OPC, PO 42.5R) conforming to the requirements of Chinese Standard GB175-2007 [9] was employed. The fly ash (FA) used was procured from Chongqing Fuling Power Plant Corporation, China. The chemical compositions of the cement and fly ash measured using Xray fluorescence are listed in Table 1. The fine aggregate was the siliceous sand with a fineness modulus of 2.60. The water reducer was the Polycarboxylic acid superplasticizer (PAS) produced by Jiangsu Subote New Materials Co., Ltd, China.

Table 1. Chemical composition of cement and fly ash fly ash (wt.\%)

\begin{tabular}{|c|c|c|c|c|c|c|c|c|c|}
\hline Composition & $\mathrm{CaO}$ & $\mathrm{Al}_{2} \mathrm{O}_{3}$ & $\mathrm{Fe}_{2} \mathrm{O}_{3}$ & $\mathrm{SiO}_{2}$ & $\mathrm{SO}_{3}$ & $\mathrm{MgO}$ & $\mathrm{Na}_{2} \mathrm{O}$ & $\mathrm{K}_{2} \mathrm{O}$ & LF \\
\hline Cement & 65.23 & 3.93 & 3.22 & 17.43 & 3.24 & 1.23 & 0.17 & 1.01 & 1.08 \\
\hline Fly ash & 3.58 & 28.76 & 3.62 & 54.03 & 0.74 & 0.54 & 0.16 & 1.17 & 1.15 \\
\hline
\end{tabular}


The mix proportions of mortar are given in Table 2. The water-binder ratio (W/B) of mortars was $0.35,0.45$ and 0.55 respectively; the replacement content of fly ash was $0,10 \%, 20 \%$ and $30 \%$ respectively and the binder-sand ratio was kept constant as 1:3 by weight. During the process of mixing and molding, it was found that the addition of fly ash increased the consistency of mortar mixture due to the greater surface area of fly ash in comparison to the cement.

The method used for compaction of mortars was as follows:

Firstly, fix the empty mold with the size of $40 \times 40 \times 160 \mathrm{~mm}^{3}$ on a vibration table. Place a layer of mortar mixture about $20 \mathrm{~mm}$ (approximately one half of the depth of the mold) in all of the rectangle compartments and then vibrate the mortar 60 times. When the vibrating of the first layer is completed, fill the compartments with the remaining mortar and then vibrate as specified for the first layer. During vibrating of the second later, bring in the mortar forced out onto the tops of the molds. After the vibration, cut off the mortar to a plane surface flush with the top of the mold by drawing the straight edge of the trowel with a sawing motion over the length of the mold.

After $24 \mathrm{~h}$ with $99 \%$ relative humidity, the mortars were demolded, and then, they were cured under water for 3,7 and 28 days.

Table 2. Mix proportions of cement mortar

\begin{tabular}{|c|c|c|c|c|c|c|}
\hline Specimen & Cement & Fly ash & Sand & Water & PAS & $W / B$ \\
\hline FA0-35 & 100 & 0 & 300 & 35 & 0.8 & 0.35 \\
\hline FA10-35 & 90 & 10 & 300 & 35 & 0.8 & 0.35 \\
\hline FA20-35 & 80 & 20 & 300 & 35 & 0.8 & 0.35 \\
\hline FA30-35 & 70 & 30 & 300 & 35 & 0.8 & 0.35 \\
\hline FA0-45 & 100 & 0 & 300 & 45 & 0.2 & 0.45 \\
\hline FA10-45 & 90 & 10 & 300 & 45 & 0.2 & 0.45 \\
\hline FA20-45 & 80 & 20 & 300 & 45 & 0.2 & 0.45 \\
\hline FA30-45 & 70 & 30 & 300 & 45 & 0.2 & 0.45 \\
\hline FA0-55 & 100 & 0 & 300 & 55 & 0 & 0.55 \\
\hline FA10-55 & 90 & 10 & 300 & 55 & 0 & 0.55 \\
\hline FA20-55 & 80 & 20 & 300 & 55 & 0 & 0.55 \\
\hline FA30-55 & 70 & 30 & 300 & 55 & 0 & 0.55 \\
\hline
\end{tabular}




\subsection{TEST METHOD}

\subsubsection{COMPRESSIVE STRENGTH}

The compressive strength tests were performed on mortars according to the Chinese standard GB/T 17671-1999 [10]. Flexural strength was tested on three specimens for each mortar type; then, six samples were obtained which were used for compressive strength testing.

\subsubsection{WATER ABSORPTION}

After the compressive strength test, the crushed mortar pieces were washed with clean water to remove the dust on surface, and the surface water was wiped off, and then the weight of sample was weighed and marked as m1. Subsequently, the pieces were placed in the vacuum drying oven, dried at $105{ }^{\circ} \mathrm{C}$ to constant weight and weighed (marked as $\mathrm{m} 0$ ). Thus, the water absorption of mortar was calculated according to Eq. (2.1).

$\beta=[(\mathrm{m} 1-\mathrm{m} 0) / \mathrm{m} 0] \times 100 \%$

\subsubsection{SEM OBSERVATION}

The crushed sample was selected, vacuum dried at $50 \mathrm{oC}$ for $48 \mathrm{~h}$, coated with gold, and finally examined by scanning electron microscopy (SEM, TESCAN VEGA 3 LMH with an acceleration voltage of $20 \mathrm{kV}$ ) to study the microstructural characteristic.

\subsubsection{TOTAL POROSITY TEST}

A mercury intrusion porosimetry (MIP, AUTOPORE IV9500, Micromeritics) test was conducted to measure the total porosity of samples. The MIP instrument was capable of a minimum intruding pressure of $1.4 \mathrm{kPa}$ and a maximum of $227 \mathrm{MPa}$.

\subsubsection{XRD ANALYSIS}

X-ray diffraction (XRD, PANalytical Empyrean using CuKa radiation, operating at $60 \mathrm{kV}$ and 55 $\mathrm{mA}$ ) was performed on powder samples to identify phase composition formed during the curing.

\section{RESULTS AND DISCUSSION}

\subsection{COMPRESSIVE STRENGTH}

The compressive strength of fly ash cement mortar with different water-binder ratio is shown in Figure 1. The compressive strength of mortar was decreased due to the addition of fly ash, especially the strength at the end of 3 and 7 days, and the strength reduction was greater with the increase of fly ash content. The hydration activity of fly ash was much lower than that of cement clinker. After partially replacing cement by fly ash, the amount of clinker minerals was decreased in 
the cementitious material system correspondingly and then the effective water-binder ratio which controlled the hydration rate of cement was increased. As a result, the $\mathrm{Ca}^{2+}$ concentration in the solution reduced and the total hydration rate of cementitious material slowed down [11-12]. Meanwhile, the hydration product particles were not closely connected with each other, thereby the early strength of mortar decreased accordingly. After 28 days of curing, the compressive strength of mortar mixed with fly ash approached that of mortar without fly ash gradually. This was because that the pozzolanic reaction of fly ash began to play a role in the later stage, and more hydration products were better intersected and connected with each other, and hence the increase rate of strength in the later stage was faster. It could also be seen from Figure 1, the compressive strength of mortar was decreased significantly with the increase of water-binder ratio.
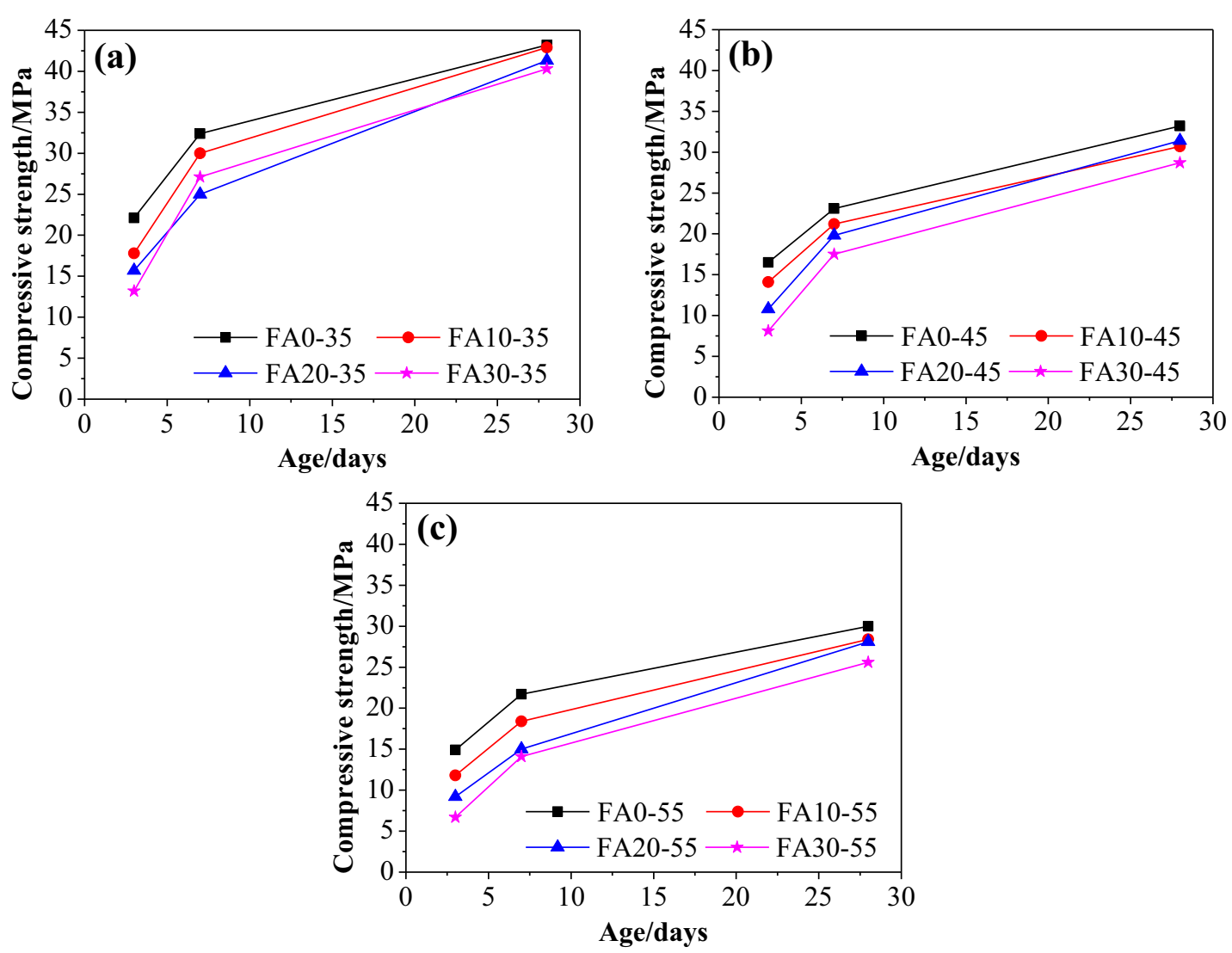

Figure 1. Compressive strength of fly ash cement mortar with different water-binder ratio: (a) $W / B=0.35$ (b) $W / B=0.45$ (c) $W / B=0.55$

\subsection{WATER ABSORPTION}

The water absorption of fly ash cement mortar with different water-binder ratio is shown in Figure 2. The water absorption of mortar was decreased with the prolonging of curing time, which was due to the increasing number of hydration products, making its structure more compact. Besides, the water 
absorption of mortar was greatly affected by the water-binder ratio. The larger the water-binder ratio was, the larger the pores left behind by the evaporation of water in the mortar would be. Therefore, the water absorption performance of mortar was better. It could also be obtained from Figure 2, adding fly ash increased the water absorption of mortar, and the water absorption increased with the increase of fly ash content. As mentioned above, the activity of fly ash was relatively low, so it couldn't exert the pozzolanic effect in the early stage [15-16], and thus its incorporation increased the porosity of mortar. However in the later stage, with the gradual hydration of fly ash, the generated hydration products would be filled in the pores of mortar [17], as a result its water absorption gradually catched up with that of mortar without fly ash.
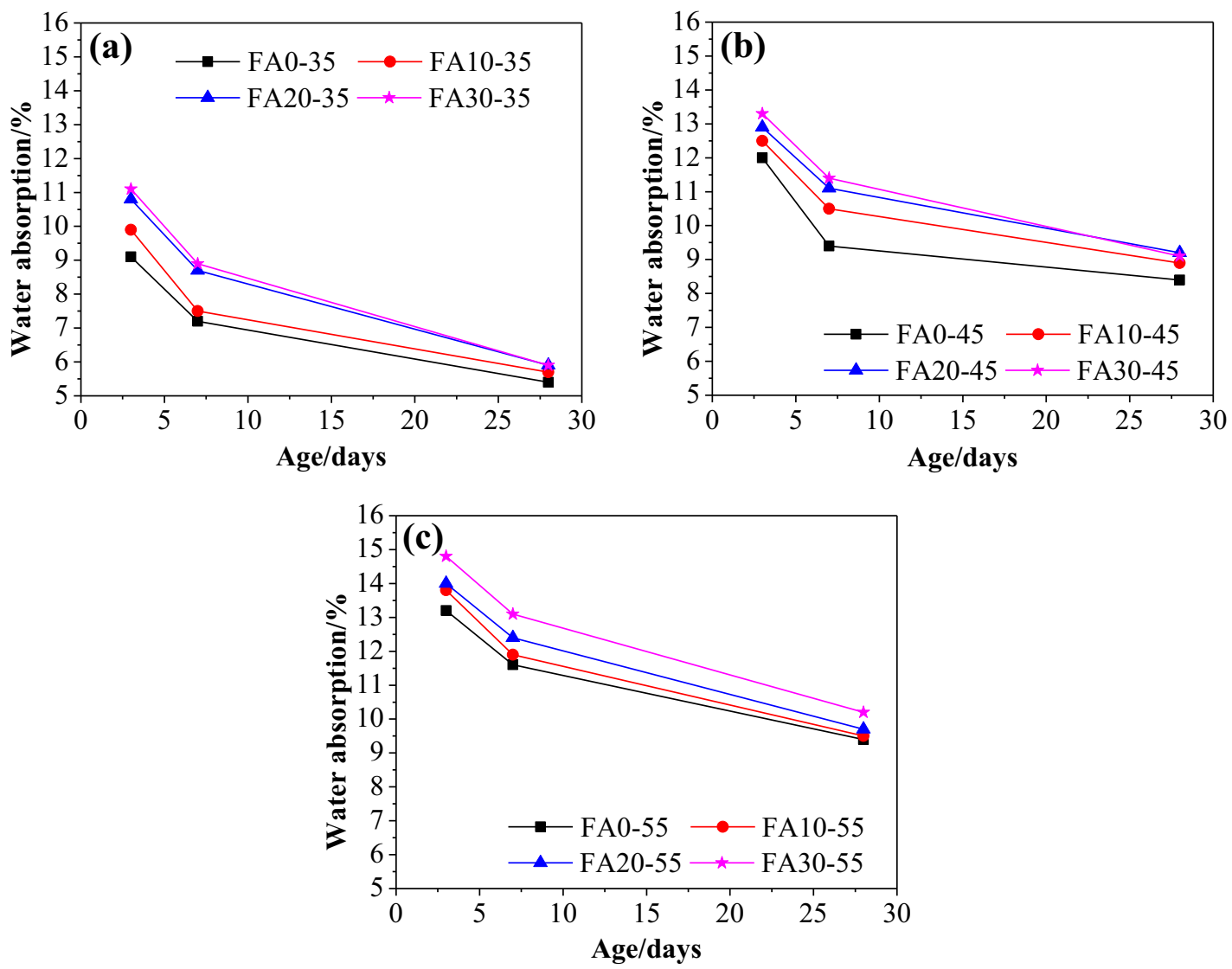

Figure 2. Water absorption of fly ash cement mortar with different water-binder ratio: (a) W/B=0.35 (b) $\mathrm{W} / \mathrm{B}=0.45$ (c) $\mathrm{W} / \mathrm{B}=0.55$

\subsection{CORRELATION BETWEEN COMPRESSIVE STRENGTH AND WATER ABSORPTION}

According to the above results, when the compressive strength of fly ash mortar increased, its corresponding water absorption decreased, and then a preliminary judgment was made that there was a correlation between the two. Subsequently, Origin software was used to conduct a linear fitting of the compressive strength and water absorption of mortar with different water-binder ratios. 
The results and fitting equations are shown in Figure 3 and Eq. (3.1) (3.3), respectively.

When the water-binder ratio is $0.35, f_{\mathrm{c} 1}=-5.323 \beta_{1}+71.879\left(R^{2}=0.983\right)$

When the water-binder ratio is $0.45, f_{\mathrm{c} 2}=-4.760 \beta_{2}+72.307\left(R^{2}=0.949\right)$

When the water-binder ratio is $0.55, f_{\mathrm{c} 3}=-4.167 \beta_{3}+68.529\left(R^{2}=0.983\right)$

where, $f_{\mathrm{c} 1}, f_{\mathrm{c} 2}$ and $f_{\mathrm{c} 3}$ are the compressive strengths of mortars with water-binder ratio of $0.35,0.45$ and 0.55 , respectively; $\beta_{1}, \beta_{2}$ and $\beta_{3}$ are the water absorptions of mortars with water-binder ratio of $0.35,0.45$ and 0.55 , respectively.
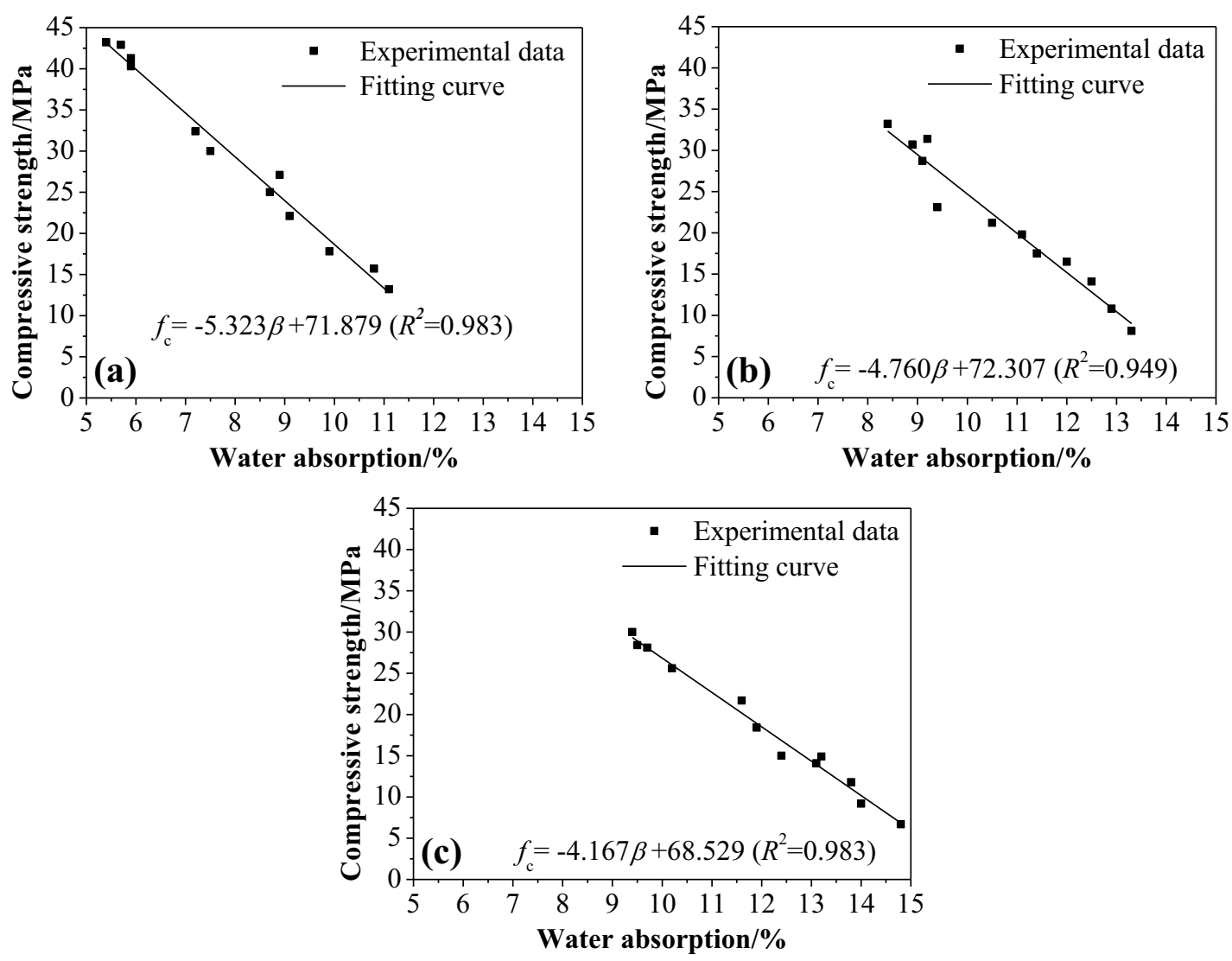

Figure 3. Fitting curves of compressive strength and water absorption of mortars with different water-binder ratio: (a) $W / B=0.35$ (b) $W / B=0.45$ (c) $W / B=0.55$

As shown in the above equations, the correlation coefficients of the fitting curves of mortar with different water-binder ratios were all higher. The slope in the fitting equation indicated the influence degree of water absorption on compressive strength. The greater the influence degree was, the higher the slope was; otherwise, the lower the slope was. It could be seen that the slopes of different water-binder ratios were not consistent, indicating that the influence degree of water absorption on compressive strength was different for the mortars with different water-binder ratios. The difference of water-binder ratio was considered in the above fitting equations, which was 
significant to predict the relationship between water absorption and compressive strength of mortar with known water-binder ratio through the equations. However, the water-binder ratio of cementbased materials may not be clear in the practical engineering. Therefore, the compressive strength $\left(f_{\mathrm{c}}\right)$ and water absorption $(\beta)$ of all mortars in this paper were further fitted linearly. The result and fitting equation are shown in Figure 4 and Eq. (3.4), respectively.

$$
f_{\mathrm{c}}=-3.838 \beta+62.332\left(R^{2}=0.904\right)
$$

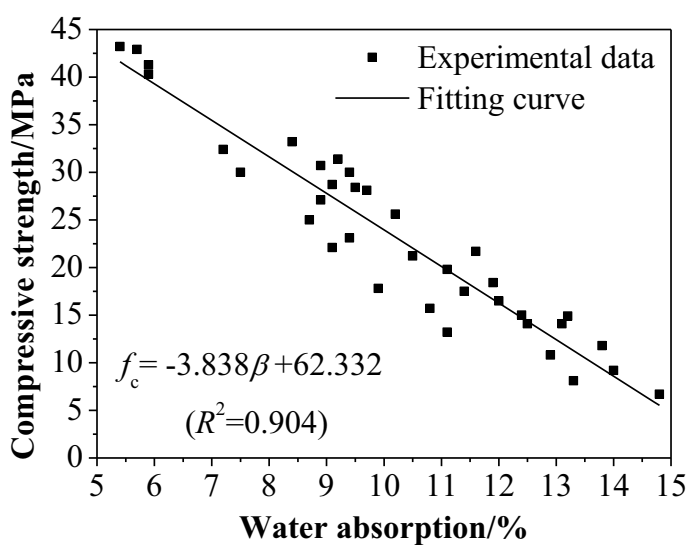

Figure 4. Fitting curves of compressive strength and water absorption of all mortars

The correlation coefficient of this equation was 0.904 , indicating that its fitting degree was also high. Therefore, when the water absorption rate of fly ash cement mortar under water immersion was measured, its corresponding compressive strength could be preliminarily inferred through Eq. (3.4), which was of great significance for detecting or identifying the stability and safety of hydraulic structures.

\subsection{SEM OBSERVATION}

The SEM images of FA0-45 and FA30-45 specimens after 28 days of water immersion are displayed in Figure 5. The C-S-H gel in the FA0-45 mortar without fly ash was compact and the overall microstructure was dense. However, the unhydrated fly ash particles still existed in the FA30-45 mortar mixed with $30 \%$ of fly ash. The effective water-binder ratio of cement-fly ash system was larger, and then the pores left by water evaporation were more obvious and the overlap of hydration products was not tighter. Hence, the loose and porous microstructure was presented in the mortar with fly ash, which resulted in the greater of water absorption and lower of compressive strength, as seen in Figures 2 and 3. 

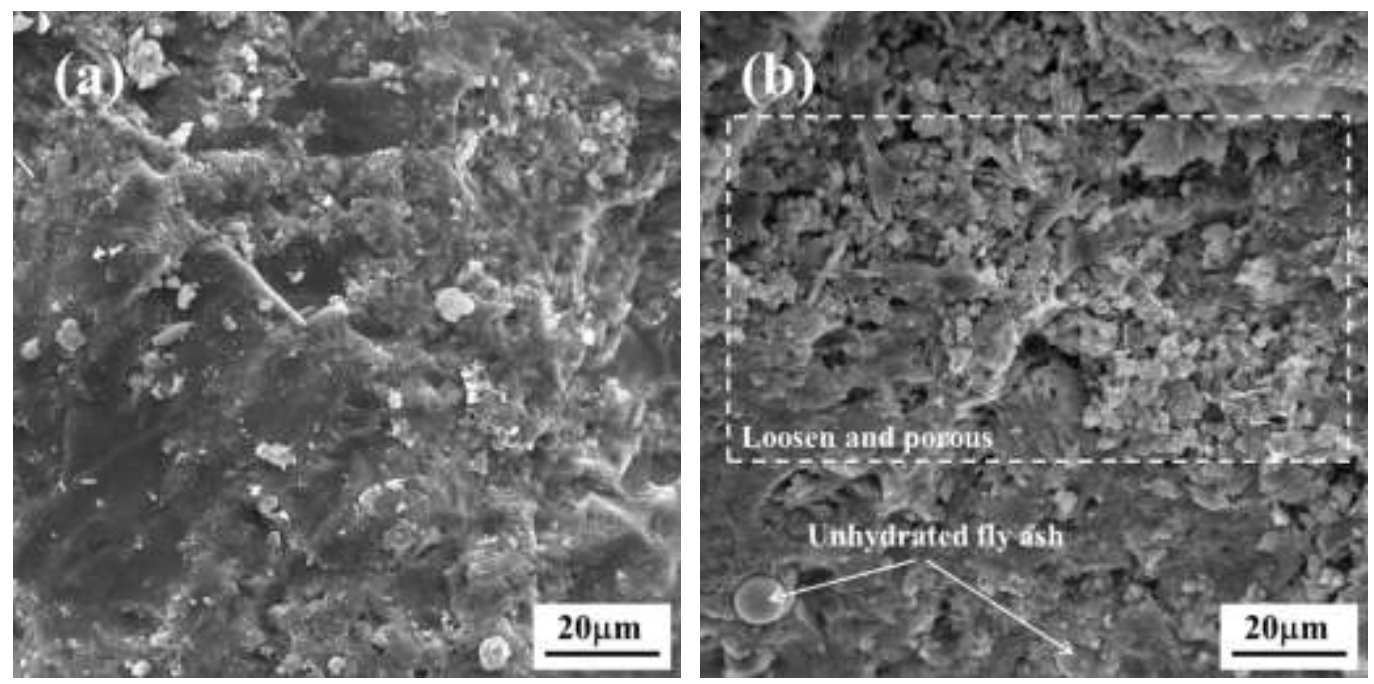

Figure 5. SEM images of mortars after 28 days of water immersion: (a) FA0-45 (b) FA30-45

\subsection{TOTAL POROSITY TEST}

The total porosity of fly ash cement mortars with the water-binder ratio of 0.45 is shown in Figure 6. At the end of 7 days, the porosity of mortar increased continuously with the increase of replacement rate of fly ash. However, the decrease of total porosity of fly ash cement mortars with age was significantly greater than that of pure cement mortar. This was attributed to that the pozzolanic effect of fly ash showed gradually in the later stage. Meanwhile, the effect of fly ash on the porosity was consistent with the water absorption as shown in Figure 2(b).

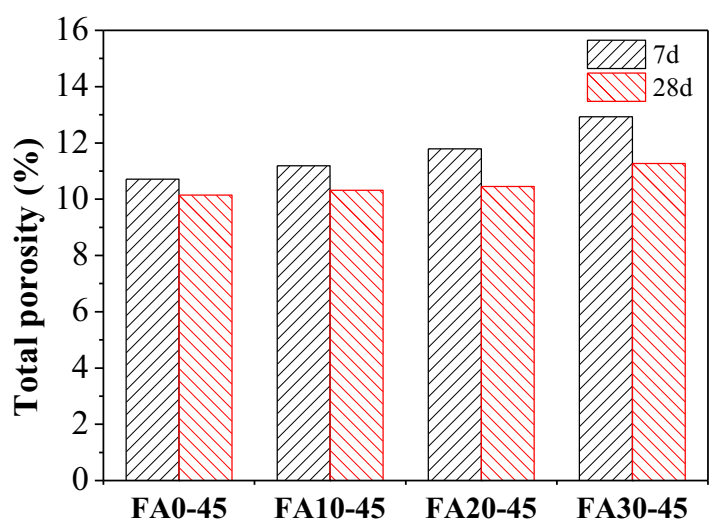

Figure 6. Total porosity of fly ash cement mortars with the water-binder ratio of 0.45

\subsection{XRD ANALYSIS}

The XRD patterns of FA0-45 and FA30-45 specimens after 28 days of water immersion are presented in Figure 7. The main mineral compositions of the two specimens were $\mathrm{SiO}_{2}, \mathrm{Ca}(\mathrm{OH})_{2}$ and $\mathrm{CaCO}_{3}$. Among them, $\mathrm{SiO}_{2}$ mainly came from the siliceous sand, and $\mathrm{CaCO}_{3}$ was produced 
from the addition mixed with cement during its production process and carbonation of cement hydration products, and $\mathrm{Ca}(\mathrm{OH})_{2}$ was formed from the hydration of cement clinker. As shown in Figure 6, the intensity of portlandite in FA30-45 mortar was lower than that in FA0-45 mortar. This was due to that the incorporation of fly ash reduced the amount of cement clinker and its corresponding hydration products. Meanwhile, part of $\mathrm{Ca}(\mathrm{OH})_{2}$ was consumed in the pozzolanic reaction of fly ash in the later stage.

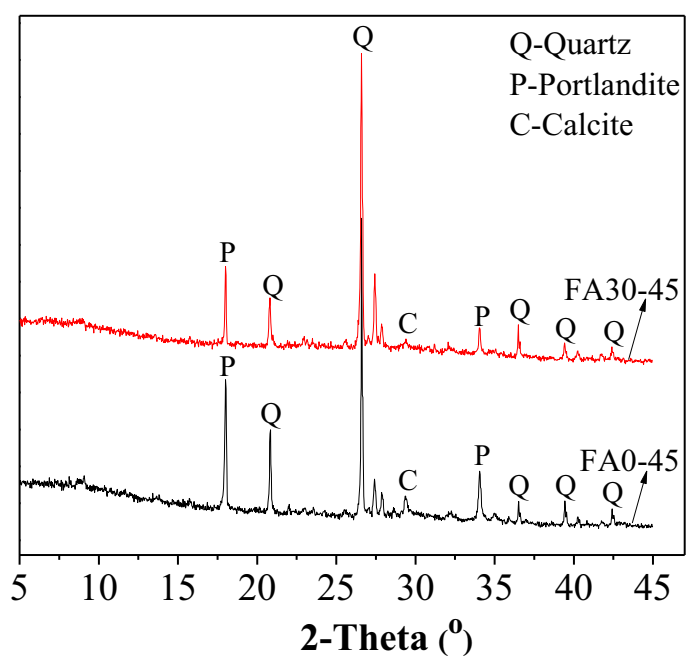

Figure 7. XRD patterns of FA0-45 and FA30-45 specimens after 28 days of water immersion

\section{Conclusions}

From the present study, the following conclusions can be drawn.

1. The reactivity of fly ash was lower than that of cement clinker, and its incorporation reduced the compressive strength of cement mortar, especially the early strength. Moreover, the strength decline was more significant with the increase of fly ash content.

2. The hydration products of cement mortar mixed with fly ash were not closely overlapped, showing a loose and porous microstructure, and its water absorption increased accordingly.

3. There was a linear correlation between the compressive strength and water absorption of mortar, and the equation is $f_{\mathrm{c}}=-3.838 \beta+62.332$, where $f_{\mathrm{c}}$ and $\beta$ represent the compressive strength and water absorption, respectively. Therefore, when the water absorption of mortar was measured, its compressive strength could be preliminarily inferred through this equation, which was of great significance for the detection and identification of the stability and safety of hydraulic structures. 


\section{ACKNOWLEDGEMENTS}

The present work was sponsored by the Scientific and Technological Research Program of Chongqing Municipal Education Commission (KJQN201801438) and the Cooperation Projects of Chunhui Plan of the Ministry of Education of China.

\section{REFERENCES}

1. J. Li, X. Zhuang, E. Monfort and et al, "Utilization of coal fly ash from a Chinese power plant for manufacturing highly insulating foam glass: Implications of physical, mechanical properties and environmental features" Construction and Building Materials, Vol.175, 2018, pp.64-76.

2. P. Chindaprasirt, S. Homwuttiwong and V. Sirivivatnanon "Influence of fly ash fineness on strength, drying shrinkage and sulfate resistance of blended cement mortar" Cement Concrete Research, Vol. 34, 2004, pp.1087-1092.

3. B. Babu and R.Thenmozhi, "An Investigation of the Mechanical Properties of Sintered Fly Ash Lightweight Aggregate Concrete (SFLWAC) with Steel Fibers” Archives of Civil Engineering, Vol.64, 2018, pp.73-85. doi: https://doi.org/10.2478/ace-2018-0005.

4. K. Sastry, A.Ravitheja and T. Reddy, "Effect of Foundry Sand and Mineral Admixtures on Mechanical Properties of Concrete" Archives of Civil Engineering, Vol.64, 2018, pp.117-131. doi: https://doi.org/10.2478/ace-2018-0008.

5. E. Horszczaruk and P. Brzozowski, "Effects of fluidal fly ash on abrasion resistance of underwater repair concrete" Wear, Vol.376-377, 2017, pp.15-21.

6. P. Dinakar, K.G. Babu and M. Santhanam, "Durability properties of high volume fly ash self-compacting concretes" Cement and Concrete Composites, Vol.30, 2008, pp.880-886.

7. D.C. Hughes, "Sulphate resistance of OPC, OPC/fly ash and SRPC pastes: pore structure and permeability" Cement Concrete Research, Vol.15, 1985, pp.1003-1012.

8. V.M. Sánchez-Fajardo, M.E. Torres and A.J. Moreno, "Study of the pore structure of the lightweight concrete block with lapilli as an aggregate to predict the liquid permeability by dielectric spectroscopy" Construction and Building Materials, Vol.53, 2014, pp.225-234.

9. GB/T 175-2007. Common Portland Cement, Chinese national standard, 2007.

10. GB/T 17671-1999. Method of testing cements-Determination of strength, Chinese national standard, 1999.

11. L. Lam, Y.L. Wong and C.S. Poon "Degree of hydration and gel/space ratio of high-volume fly ash/cement Systems" Cement Concrete Research, Vol.30, 2000, pp.747-756.

12. H.D. Yan, W. Sun and Y.M. Zhang "Hydration of high-volume fly ash cement pastes" Cement and Concrete Composites, Vol.22, 2000, pp.445-452.

13. Q. Huang, C. Wang, Q. Zeng and et al "Deterioration of mortars exposed to sulfate attack under electrical field" Construction and Building Materials, Vol. 117, 2016, pp.121-128.

14. E. Sakai, S. Miyahara, S. Ohsawa and et al "Hydration of fly ash cement" Cement Concrete Research, Vol.35, 2005, pp.1135-1140.

15. P. Termkhajornkit, T. Nawa and K. Kurumisawa "Effect of water curing conditions on the hydration degree and compressive strengths of fly ash-cement paste" Cement and Concrete Composites, Vol.28, 2006, pp.781789.

16. Q. Huang, C. Wang, C. Yang and et al "Accelerated sulfate attack on mortars using electrical pulse" Construction and Building Materials, Vol.95, 2015, pp.875-881.

17. C.S. Poon, Y.L. Wong and L. Lam "The influence of different curing conditions on the pore structure and related properties of fly-ash cement pastes and mortars" Construction and Building Materials, Vol.11, 1997, pp.383-393. 


\section{LIST OF FIGURES AND TABLES:}

Fig. 1. Compressive strength of fly ash cement mortar with different water-binder ratio: (a) $W / B=0.35$ (b) $W / B=0.45$ (c) $W / B=0.55$

Fig. 2. Water absorption of fly ash cement mortar with different water-binder ratio: (a) $W / B=0.35$ (b) $W / B=0.45$ (c) $W / B=0.55$

Fig. 3. Fitting curves of compressive strength and water absorption of mortars with different water-binder ratio: (a) $W / B=0.35$ (b) $W / B=0.45$ (c) $W / B=0.55$

Fig. 4. Fitting curves of compressive strength and water absorption of all mortars

Fig. 5. SEM images of mortars after 28 days of water immersion: (a) FA0-45 (b) FA30-45

Fig. 6. Total porosity of fly ash cement mortars with the water-binder ratio of 0.45

Fig. 7. XRD patterns of FA0-45 and FA30-45 specimens after 28 days of water immersion

Tab. 1. Chemical composition of cement and fly ash fly ash (wt.\%)

Tab. 2. Mix proportions of cement mortar 